\title{
Beyond coverage: improving the quality of antenatal care delivery through integrated mentorship and quality improvement at health centers in rural Rwanda
}

Anatole Manzi ${ }^{1,2,3^{*}}$ (D), Laetitia Nyirazinyoye ${ }^{3}$, Joseph Ntaganira ${ }^{3}$, Hema Magge ${ }^{4,5,6}$, Evariste Bigirimana ${ }^{7}$, Leoncie Mukanzabikeshimana ${ }^{7}$, Lisa R. Hirschhorn ${ }^{8}$ and Bethany Hedt-Gauthier ${ }^{1,9}$

\begin{abstract}
Background: Inadequate antenatal care (ANC) can lead to missed diagnosis of danger signs or delayed referral to emergency obstetrical care, contributing to maternal mortality. In developing countries, ANC quality is often limited by skill and knowledge gaps of the health workforce. In 2011, the Mentorship, Enhanced Supervision for Healthcare and Quality Improvement (MESH-QI) program was implemented to strengthen providers' ANC performance at 21 rural health centers in Rwanda. We evaluated the effect of MESH-QI on the completeness of danger sign assessments.

Methods: Completeness of danger sign assessments was measured by expert nurse mentors using standardized observation checklists. Checklists completed from October 2010 to May $2011(n=330)$ were used as baseline measurement and checklists completed between February and November 2012 (12-15 months after the start of MESH-QI implementation) were used for follow-up. We used a mixed-effects linear regression model to assess the effect of the MESH-Ql intervention on the danger sign assessment score, controlling for potential confounders and the clustering of effect at the health center level.

Results: Complete assessment of all danger signs improved from 2.1\% at baseline to 84.2\% after MESH-QI ( $p<0.001)$. Similar improvements were found for 20 of 23 other essential ANC screening items. After controlling for potential confounders, the improvement in danger sign assessment score was significant. However, the effect of the MESH-QI was different by intervention district and type of observed ANC visit. In Southern Kayonza District, the increase in the danger sign assessment score was 6.28 (95\% Cl: 5.59, 6.98) for non-first ANC visits and 5.39 (95\% Cl: 4.62, 6.15) for first ANC visits. In Kirehe District, the increase in danger sign assessment score was 4.20 (95\% Cl: 3.59, 4.80) for non-first ANC visits and 3.30 (95\% Cl: 2.80, 3.81) for first ANC visits.

Conclusion: Assessment of critical danger signs improved under MESH-QI, even when controlling for nurse-mentees' education level and previous training in focused ANC. MESH-QI offers an approach to enhance quality of care after traditional training and may be an approach to support newer providers who have not yet attended content-focused courses.
\end{abstract}

\footnotetext{
* Correspondence: mangano2020@gmail.com

${ }^{1}$ Partners In Health, Kigali, Rwanda

${ }^{2}$ Partners In Health, Boston, USA

Full list of author information is available at the end of the article
} 


\section{Background}

With the introduction of the millennium development goals (MDGs) in 2000, maternal death has been a focus of clinical and public health interventions globally [1-3]. Despite numerous clinical and public health interventions, the highest maternal mortality is still reported in subSaharan Africa [4], where poor quality healthcare contributed to failure to reach the MDG5 goal to reduce maternal and child mortality by three-quarters by 2015 [5-7]. This inadequate decline of maternal mortality in developing countries [8] calls for improved coverage and quality in health care for pregnant women.

Antenatal care (ANC) was initiated in the twentieth century as a strategy to prevent or ensure early treatment of pregnancy complications through systematic assessments, women's education on positive behaviors, gestational age assessment, screening for fetal development and early detection of mother and baby abnormalities $[6,9]$. There is evidence that ANC has the potential to reduce maternal mortality especially in low resource settings [10-12]. However, the quality of ANC is often hindered by gaps in knowledge and skills of care providers [13-17]. A study comparing thirty-eight countries found gaps in the quality of antenatal care delivery, including limited danger sign assessment and poor provision of essential counseling messages [18].

In Rwanda and other developing countries, poor quality of care is often exacerbated by the lack of basic equipment and low performance of health care workers [19-21]. While over $80 \%$ of the burden of diseases is addressed by health center nurses [22], the Africa Health Workforce Observatory estimated that Rwanda has only 1 nurse per 1493 people [23]. Such a low density of skilled professionals affects the overall quality of care at health center level. Although more than half of maternal deaths could be averted by adequate assessments and management of danger signs during ANC visits [9, 24-26], innovative strategies are needed to improve core maternal health care delivery processes $[27,28]$.

\section{Focused antenatal care training and supervision}

In 2002, the World Health Organization adopted focused antenatal care (FANC) as a proactive strategy to detect and address critical needs for the mother and fetal wellbeing [29]. The goal of FANC is to identify opportunities for education and prevention or early management of problems that could affect pregnancy outcomes. In contrast to traditional ANC, FANC targets the individualized needs rather than relying solely on the frequency of ANC visits.

In 2003, Rwanda launched the implementation of FANC [30]. Health center providers attended classroom-based trainings that include a comprehensive review of ANC screenings so that these providers could develop an individualized child birth plan with each pregnant woman [31-33].

In Rwanda, in addition to FANC training, routine supervision visits were implemented as a strategy to facilitate the implementation of FANC. The Rwandan Ministry of Health recommended monthly supervision visits from district hospital $(\mathrm{DH})$ 's maternal and child health supervisors to health center-based ANC providers. Despite FANC trainings and routine supervision visits in Rwanda, there remained inconsistent and incomplete danger sign assessments during ANC visits, as has been observed in other countries in the region [22, 34-40]. We hypothesized that ongoing mentorship could address this gap by converting ANC assessment and management knowledge and skills into practice.

Historically, Rwanda has three main education tracks for nurses and midwives including A2, A1, and A0. A2 level nurses and midwives are trained to the secondary school level and covers basic clinical subjects and specific area of nursing specialties [41]. Since 2006, the Ministry of Health stopped training and deploying A2 level nurses and midwives, deeming their skill sets not sufficient to deliver high quality care services. Therefore, the ongoing efforts to upgrade A2 to A1 or A0 level may take several years [42]. In the meantime, A2 level nurses remain the bulk of nursing care at health center, fulfilling three functions including health promotion, preventative services provision, and primary healthcare delivery $[43,44]$.

\section{The MESH-QI intervention}

Partners In Health $(\mathrm{PIH})$ in collaboration with the Rwandan Ministry of Health $(\mathrm{MoH})$ implemented a clinical Mentorship, Enhanced Supervision for Healthcare and Quality Improvement (MESH-QI) Program to improve the quality of care and systems in rural health centers in Rwanda [45]. During health center visits, MESH-QI mentors delivered provider-centered support including side-byside mentorship, bedside teaching and clinical case review to improve knowledge, skills and effective communication techniques. All ANC providers, regardless of their training background, received mentorship visits every four to six weeks. In addition to mentorship, health center providers were coached on quality improvement, using Plan-DoStudy-Act cycle methodology, to help providers address facility issues that affected quality of maternal healthcare delivery [45]. The MESH-QI package is provided by expert nurse mentors with extensive experience as providers in specific clinical areas. These mentors are $\mathrm{MoH}$ employees who were trained in coaching and provided with ongoing support from an experienced gynecologist obstetrician, expert midwife and PIH's QI specialist.

Previous evaluations have demonstrated that the MESHQI model improved assessments and diagnosis across a variety of clinical programs, including the Integrated 
Management of Childhood Illness (IMCI), Prenatal Care and Integrated Management of Adolescent and Adulthood Illness (IMAI) and HIV $[45,46]$. A qualitative study found positive perceptions and acceptability of the MESH-QI model from the perspective of the mentors, health care workers and district hospital managers, building health workers' confidence in clinical diagnosis and case management [47].

In this study, we assess the impact of the MESH-QI intervention on the completeness of ANC assessment items, with a focus on danger signs. To our knowledge, no studies have evaluated the effectiveness of provider and systems-focused mentoring interventions to improve the quality of ANC at health centers in rural, sub-Saharan Africa. Our study findings could inform policy makers, managers and ANC providers wishing to improve the quality of ANC through integration of mentorship-based interventions in similar settings.

\section{Methods}

\section{Study design and setting}

This cross-sectional, pre-post study assesses the effect of MESH-QI on the completeness of ANC assessment items in rural Rwanda. We include all $21 \mathrm{PIH}$-supported public health centers, 8 in Southern Kayonza District and 13 in Kirehe District, collectively serving over 500,000 people [48]. These health centers, which are managed by the Rwandan $\mathrm{MoH}$, were generally staffed by A2-level nurses (education level equivalent to secondary/high school) $[49,50]$. All nurses working in the ANC clinic were eligible for mentoring and observation.

\section{Data collection}

Baseline measurements were completed by the expert nurse mentors from October 2010 to May $2011(n=330)$ prior to any mentoring intervention to understand the pre-intervention clinical care activities. The follow-up measurement was completed by the mentors during support visits from February to November $2012(n=292)$, 12-15 months after the start of the MESH-QI intervention. The mentor observation checklists were adapted from the standards described in the Rwandan national ANC screening tool used at all health centers [51]. This tool listed the essential ANC assessment items including medical history, screening for seven danger signs (headache, blurry vision, facial swelling, convulsions, bleeding, loss of fluid, and painful contractions), measurement of vital signs, assessment of fetal well-being, communication and counseling [52].

\section{Data analysis}

Data were analyzed using Stata v12 (College Station, TX: StataCorp LP).We use frequencies and percents to describe the nurse-mentee and facility characteristics. For all assessment areas, we compared completeness of assessment at baseline and after MESH-QI using the Chi-squared test.

The unit of analysis was the clinical encounter. The outcome of this study was the danger sign assessment score calculated based on equal weighting of the completion of each of the seven key danger sign assessments $(0$ indicating no danger sign was assessed and 7 indicating that all seven danger signs were assessed). We used interaction terms to assess whether the intervention district, completion of FANC training, level of nurse-mentee's education, or type ANC visit (first or non-first ANC visit) modified the effect of the MESH-QI intervention. The interaction term was included in the final model if the interaction term variable was significant at the $\alpha=$ 0.05 level in bivariate analyses. We performed a multivariable linear regression analysis to assess the effect of MESH-QI on the danger sign assessment score, controlling for the following potential confounders: district (Southern Kayonza/Kirehe), nurse-mentee's education level, nurse-mentee's FANC training and type of ANC visit under observation (first vs others). Because a nurse could lead multiple clinical encounters, we used a random effect to account for clustering among observed ANC consultations conducted by the same nurse.

\section{Results}

Observations were completed on 330 ANC visits conducted by 45 different nurses at baseline and 292 visits conducted by 35 different nurses during the follow-up period (Table 1). The number of nurses who had received FANC training varied over time; at baseline, 20 (44\%) out of the 45 nurses had been trained in FANC compared to 21 (60\%) out of 35 during follow-up period. Forty-three nurses (96\%) at baseline had an A2 (high school) education compared to 32 (91\%) during follow-up period. The remaining nurses had A1 (two to three years of postsecondary education as defined by the Rwanda Education Council) education.

For each of the seven danger sign assessment items, there was a significant improvement in completion at follow-up compared to baseline $(p<0.001)$ (Table 2). Overall the improvement in women with all danger signs assessed significantly improved, from $2.1 \%$ at baseline to $84.0 \%$ at follow-up $(p<0.001)$. Significant improvements were also found across other ANC assessment items. Observed ANC visits where nurses checked all vital signs and fetal wellbeing assessment items (fundal height, heart rate, movement, and position) improved significantly (1\% to $55 \%, 37 \%$ to $89 \%$, respectively, $p<0.001)$. Completeness of counseling improved significantly as well (2.2\% to $51.0 \%, p<0.001)$. Medical history assessment including previous surgeries, current medications, use of traditional medications, tobacco, and alcohol, domestic violence, and 
Table 1 Demographics, study population, and case-observation characteristics

\begin{tabular}{|c|c|c|c|c|}
\hline & \multicolumn{2}{|c|}{ Baseline } & \multicolumn{2}{|c|}{ Follow-up } \\
\hline & $\overline{\#}$ & $\%$ & $\#$ & $\%$ \\
\hline \multicolumn{5}{|l|}{ Demographics } \\
\hline Number of health facilities & 21 & & 21 & \\
\hline Number of nurses observed & 45 & & 35 & \\
\hline Number of observations & 330 & & 292 & \\
\hline \multicolumn{5}{|l|}{ Nurse characteristics } \\
\hline \multicolumn{5}{|l|}{ District } \\
\hline Southern Kayonza & 18 & 40 & 8 & 23 \\
\hline Kirehe & 27 & 60 & 27 & 77 \\
\hline FANC trained & 20 & 44 & 21 & 60 \\
\hline A2 level of education ${ }^{a}$ & 43 & 96 & 32 & 91 \\
\hline \multicolumn{5}{|l|}{ Case-observation characteristics } \\
\hline $\begin{array}{l}\text { Average number of observed cases per } \\
\text { health center }\end{array}$ & 16 & & 14 & \\
\hline \multicolumn{5}{|l|}{ Antenatal care visit } \\
\hline First & 159 & 48 & 93 & 32 \\
\hline Others & 171 & 52 & 199 & 68 \\
\hline Nurse providers trained in $\mathrm{FANC}^{\mathrm{C}}$ & 164 & 50 & 166 & 57 \\
\hline \multicolumn{5}{|l|}{ Nurse's education level } \\
\hline $\mathrm{A} 2^{\mathrm{a}}$ & 317 & 96 & 266 & 91 \\
\hline $\mathrm{A} 1^{\mathrm{b}}$ & 13 & 4 & 26 & 9 \\
\hline
\end{tabular}

${ }^{\mathrm{a}} \mathrm{A} 2$ level is a high school (secondary) level as defined by Rwanda education council

${ }^{\mathrm{b}} \mathrm{A} 1$ is two to three years of post-secondary education as defined by Rwanda education council

${ }^{C}$ FANC: Focused antenatal care including a thorough individualized surveillance of the pregnant woman, systematic screening of conditions and diseases, detection and management of pregnancy-related complications, and provision of counseling, preventive measures and support plan essential for safe pregnancy and delivery

checking and documenting HIV status had less improvement, although the change was significant $(2.1 \%$ to $14.0 \%$, $p<0.001)$. No significant improvement was seen in proportion of observed cases assessed for previous surgery ( $28 \%$ to $29 \%, p=0.796$ ). The assessment of fetal heart rate remained high at both baseline and follow-up period ( $98 \%$ to $97 \%, p=0.914$ ).

The effect of MESH-QI on the danger sign assessment score was modified by district and type of ANC visit ( $p$-value for interaction $<0.001$, Table 3$)$. No significant interaction was found between the effect of MESH-QI and FANC training $(p=0.436)$ and level of mentee's education $(p=0.101)$. After controlling for level of mentee's education and FANC training and clustering at nurse level, the MESH-QI intervention remained associated with significant improvement in the danger sign assessment score (Table 4). However, the effect of the MESH-QI intervention on the danger sign assessment score was different for each district and type of ANC visit: For
Southern Kayonza District, the predicted increase in danger sign assessment score under MESH-QI was 6.28 (95\% CI: 5.59, 6.98; $p<0.001)$ for non-first ANC visits, and $5.39(4.62,6.15 ; p<0.001)$ for first ANC visits. For Kirehe District, the predicted increase in danger sign assessment score was 4.20 (95\% CI: 3.59, 4.80; $p<0.001$ ) for non-first ANC and 3.30 (95\% CI: 2.80, 3.81; $p<0.001$ ) for first ANC visits.

\section{Discussion}

Although ANC represents an important opportunity to detect danger signs during pregnancy [26] and ensure appropriate management of pregnancy risks [53], there is a need of attention to quality of ANC delivery in resourcelimited settings. This study's findings demonstrate that MESH-QI model strengthens the quality of ANC as measured by improvement in the danger sign assessment score. The observed improvements persist even when controlling for FANC-training status and level of nursementee's education, and were greater for non-first ANC visits, both of which had lower danger sign assessment scores at baseline. The findings suggest MESH-QI as a promising intervention to improve components of quality of care in resource-limited settings facing staffing challenges including low levels of training and education. These results are consistent with the growing evidence highlighting the need for enhanced and effective supervision after didactic trainings [19].

Although overall danger sign assessments and most other assessment items were more likely to be completed under MESH-QI, some screening areas did not improve. For fetal position and heart rate, the completeness was high at baseline and stayed persistently high. For history assessment, even though there was a significant improvement during the MESH-QI intervention period, the levels of completeness under MESH-QI remained poor. We have several hypotheses that could explain this result. First, mentors may have emphasized strengthening danger sign assessments assuming that the woman's history was already known from previous visits. Furthermore, nurse-mentees were residents of the health center catchment area, and it is possible that they had opportunities to interact with women outside of clinic and therefore deprioritized a systematic woman's history assessment during ANC visit. The lack of essential tools to guide clinical supervision may have led to notable inconsistencies prior to MESH-QI intervention. The use of standardized checklists as part of MESH-QI intervention helped to assess and improve nurse-mentee's competencies and address systems gaps.

This study has important limitations to consider in interpreting results. First, the pre-post design without a control means that we cannot make definitive conclusions about attribution. However, there were no other 
Table 2 Completeness of antenatal care assessments before and after MESH-QI intervention

\begin{tabular}{|c|c|c|c|c|c|}
\hline & \multicolumn{2}{|c|}{ Baseline } & \multicolumn{2}{|c|}{ Follow-up } & \multirow[t]{2}{*}{$P$-value } \\
\hline & $n$ & $\%$ & $n$ & $\%$ & \\
\hline \multicolumn{6}{|l|}{ Danger signs } \\
\hline Headache & 79 & 24.0 & 278 & 95.2 & $<0.001$ \\
\hline Blurry vision & 77 & 23.3 & 278 & 95.2 & $<0.001$ \\
\hline Facial swelling & 184 & 56.0 & 290 & 99.3 & $<0.001$ \\
\hline Convulsions & 57 & 17.3 & 275 & 94.1 & $<0.001$ \\
\hline Bleeding & 134 & 41.0 & 285 & 98.0 & $<0.001$ \\
\hline Loss of fluid & 76 & 23.0 & 267 & 91.4 & $<0.001$ \\
\hline Painful contractions & 91 & 28.0 & 264 & 90.4 & $<0.001$ \\
\hline Composite & 7 & 2.1 & 246 & 84.2 & $<0.001$ \\
\hline \multicolumn{6}{|l|}{ Medical history } \\
\hline Previous surgeries & 92 & 28.0 & 85 & 29.0 & 0.734 \\
\hline Current medications & 11 & 3.3 & 41 & 14.0 & $<0.001$ \\
\hline Traditional medications/herbs & 7 & 2.1 & 41 & 14.0 & $<0.001$ \\
\hline Tobacco use & 8 & 2.4 & 38 & 13.1 & $<0.001$ \\
\hline Alcohol & 10 & 3.0 & 39 & 13.5 & $<0.001$ \\
\hline Domestic violence & 17 & 5.2 & 36 & 12.5 & 0.001 \\
\hline HIV status checked and documented & 66 & 42.0 & 80 & 86.0 & $<0.001$ \\
\hline Composite & 7 & 2.1 & 40 & 14.0 & $<0.001$ \\
\hline \multicolumn{6}{|l|}{ Vital signs } \\
\hline Temperature & 85 & 26.0 & 213 & 74.0 & $<0.001$ \\
\hline Blood pressure & 289 & 88.0 & 288 & 99.0 & $<0.001$ \\
\hline Pulse & 111 & 34.0 & 273 & 93.5 & $<0.001$ \\
\hline Respirations & 13 & 4.0 & 172 & 60.0 & $<0.001$ \\
\hline Composite & 3 & 1.0 & 160 & 55.0 & $<0.001$ \\
\hline \multicolumn{6}{|l|}{ Fetal well being } \\
\hline Fundal height $^{\dagger}$ & 167 & 98.0 & 199 & 100.0 & 0.030 \\
\hline Heart rate $(\mathrm{BCF})^{\dagger}$ & 167 & 98.0 & 194 & 97.5 & 0.914 \\
\hline Movement (after 20 weeks) $)^{\dagger}$ & 80 & 47.0 & 197 & 99.0 & $<0.001$ \\
\hline Position (after 36 weeks) ${ }^{\ddagger}$ & 82 & 95.4 & 89 & 98.0 & 0.367 \\
\hline Composite & 121 & 37.0 & 259 & 89.0 & $<0.001$ \\
\hline \multicolumn{6}{|l|}{ Counseling } \\
\hline Needed supplies are available & 224 & 68.0 & 215 & 75.0 & 0.050 \\
\hline Counseling occurs in private room & 304 & 92.1 & 288 & 99.0 & $<0.001$ \\
\hline Makes eye contact with woman & 291 & 88.1 & 287 & 98.2 & $<0.001$ \\
\hline Speaks to woman in respectful manner & 316 & 96.0 & 289 & 99.0 & 0.014 \\
\hline Uses words that woman can understand & 294 & 89.0 & 285 & 98.0 & $<0.001$ \\
\hline Concrete response provided & 78 & 24.0 & 199 & 68.0 & $<0.001$ \\
\hline Explains all medical procedures & 44 & 13.3 & 269 & 93.4 & $<0.001$ \\
\hline Composite & 7 & 2.2 & 149 & 51.0 & $<0.001$ \\
\hline
\end{tabular}

${ }^{\dagger} N=171$ for baseline and $N=199$ for follow-up

${ }^{\ddagger} N=86$ for baseline and $N=91$ for follow-up

ANC-targeted quality improvement work in the two districts and no changes in national ANC strategy or other ANC-focused interventions during the study period other than periodic FANC training or increased nurse education, which we controlled for in the final analysis. Another limitation is that we relied on performance measurements 
Table 3 Relationship between demographic characteristics and danger sign assessment score and mentoring period, stratified by demographics characteristics

\begin{tabular}{llll}
\hline \multirow{2}{*}{ Predictors } & Bivariate analysis & $\begin{array}{l}\text { P-value for } \\
\text { interaction } \\
\text { term }\end{array}$ \\
\cline { 2 - 3 } & $\begin{array}{l}\text { Changes in ANC } \\
\text { Assessment Score }\end{array}$ & $95 \% \mathrm{Cl}$ & \\
\hline Distict & & ten
\end{tabular}

District

$<0.001$

Southern Kayonza

\begin{tabular}{|c|c|c|}
\hline Baseline & Ref. & \\
\hline Post-MESH-QI & 6.06 & {$[5.43,6.69]$} \\
\hline \multicolumn{3}{|l|}{ Kirehe } \\
\hline \multicolumn{3}{|l|}{ Baseline } \\
\hline Post-MESH-QI & 3.88 & {$[3.46,4.30]$} \\
\hline \multicolumn{3}{|l|}{ EANC Training } \\
\hline \multicolumn{3}{|c|}{ Received FANC Training } \\
\hline Baseline & Ref. & \\
\hline Post-MESH-QI & 4.75 & {$[4.15,5.35]$} \\
\hline \multicolumn{3}{|c|}{ Did not receive FANC training } \\
\hline Baseline & Ref. & \\
\hline Post-MESH-QI & 4.47 & {$[4.03,4.91]$} \\
\hline \multicolumn{3}{|c|}{ evel of education } \\
\hline \multicolumn{3}{|l|}{ ligh education } \\
\hline Baseline & Ref. & \\
\hline Post-MESH-QI & 5.90 & {$[4.27,7.54]$} \\
\hline \multicolumn{3}{|c|}{ Secondary education } \\
\hline Baseline & Ref. & \\
\hline Post-MESH-QI & 4.50 & {$[4.13,4.87]$} \\
\hline
\end{tabular}

ANC visit

First ANC visits

Baseline Ref.

Post-MESH-QI $\quad 5.05$

Other ANC visits

Baseline Ref.

Post-MESH-QI $\quad 3.84 \quad[3.38,4.30]$

Table 4 Changes in danger sign assessment score post-MESH-QI intervention $^{a}$

\begin{tabular}{|c|c|c|}
\hline & $\begin{array}{l}\text { Changes in assessment } \\
\text { score }\end{array}$ & $95 \% \mathrm{Cl}$ \\
\hline $\begin{array}{l}\text { The effect of MESH-QI, Kirehe, } \\
\text { non-first ANC }\end{array}$ & 4.20 & {$[3.59,4.80]$} \\
\hline $\begin{array}{l}\text { The effect of MESH-QI, Kayonza, } \\
\text { non-first ANC }\end{array}$ & 6.28 & {$[5.59,6.98]$} \\
\hline $\begin{array}{l}\text { The effect of MESH-QI, Kirehe, } \\
\text { first ANC }\end{array}$ & 3.30 & {$[2.80,3.81]$} \\
\hline $\begin{array}{l}\text { The effect of MESH-QI, Kayonza, } \\
\text { first ANC }\end{array}$ & 5.39 & {$[4.62,6.15]$} \\
\hline
\end{tabular}

collected during routine mentoring visits by mentors themselves, who may introduce bias in their observation of ANC assessments. Furthermore, a Hawthorne effect may have caused ANC nurses to perform better as a result of being observed resulting in overestimates of the overall effect of the MESH-QI intervention. However, mentors were trained in relationship building and other techniques as part of their orientation. We believe this reassured nurse-mentees so that they were able to provide their usual care without fear of judgment.

In the efforts to promote the universal health coverage, Rwanda successfully launched a community-based health insurance scheme, "Mutuelle" [54]. Local district officials incorporated mutuelle on the list of targets for district performance contracts locally known as "Imihigo" [55]. This study's baseline data were collected during the evaluation of the district performance [56], a period marked by intensive efforts deployed by districts to accelerate the pace toward performance goals. This efforts may have increased mutuelle enrollments, leading to increased utilization of health center services. Furthermore, an increased workload may have caused an intra-clinic pressure with indirect effect on baseline findings. As such, nurses may have rushed to complete consultations with limited time to focus on recommended ANC practices.

Finally, we sought to assess the effect of the MESH-QI model on danger sign assessments and other ANC screenings. We assume that improving key ANC assessments has improved case management. Further studies are needed to assess the effect of the MESH-QI intervention on pregnancy outcomes. Future studies should also assess the impact of the MESH-QI on other aspects of the nurse-mentees including satisfaction, retention and perceived impact on their clinical competencies. Future studies should also assess the impact of the MESH-QI on other aspects of nurse-mentees' experiences including satisfaction, retention and perceived impact on their clinical competencies. Moreover, we recommend exploring the experiences of pregnant women using ANC services and the impact of MESH-QI on these experiences. This information is crucial to understand their perceptions as well as improvements needed to better meet patient expectations.

While ANC is critical to strengthen maternal and newborn health outcomes, the failure of training and supervision to improve the quality of care suggests the need for evidence-based interventions to improve ANC quality in sub-Saharan Africa [57]. This study demonstrates the benefits of a mentorship intervention, MESH-QI, to improve the quality of ANC at rural health centers. As such, this constitutes an invaluable contribution to the WHO's goal to have a world where "every pregnant woman and newborn receives quality care throughout the pregnancy, childbirth and the postnatal period" [58] and is consistent with 
their recommendation to promote health systems interventions that improve the utilization and quality of ANC [59].

\section{Conclusion}

In resource-constrained settings where the application of clinical skills constitutes a major challenge, MESH-QI could be an effective model to improve the quality of ANC and increase the opportunities to early detect and manage pregnancy complications.

This study highlights the importance of post-training mentoring and quality improvement rather than relying solely on didactic trainings and traditional supervision. Further, updated guidelines and observation checklists are key for mentors or supervisors to have a systematic view of ANC and provide feedback. In order to sustain these improvements, efforts are underway to integrate the MESH-QI checklists and quality of care indicators into routine district supervision and health management information system.

\section{Abbreviations \\ DH: District hospital; FANC: Focused antenatal care; IMAI: Integrated Management of Adolescent and Adulthood IIIness; IMCl: Integrated Management of Childhood Illness; MDGs: Millennium development goals; MESH-Ql: Mentorship, enhanced supervision for healthcare and quality improvement; $\mathrm{MoH}$ : Ministry of Health; $\mathrm{MoH}$ : Ministry of Health; PIH: Partners In Health}

\section{Acknowledgements}

This study could not have been accomplished without the ongoing support and dedication of MESH-QI mentors, ANC providers, Kirehe and Southern Kayonza Districts' clinical leadership and MESH-QI technical advisors. BHG received support from the Department of Global Health and Social Medicine Research Core at Harvard Medical School.

\section{Funding}

This study was supported by funds from the African Health Initiative of the Doris Duke Charitable Foundation (Grant no. 200905).

\section{Availability of data and materials}

The datasets analyzed during the current study are available from the corresponding author upon reasonable request.

\section{Authors' contributions}

AM conceived the study. EB and LM collected the data. AM, LRH, and BHG participated in the data analysis and interpretation. $A M, L N, J N$, and $L R H$ participated in the study design and manuscript preparation. All authors read and approved the final manuscript.

\section{Ethics approval and consent to participate}

This study is covered through Population Health Implementation and Training Partnership research protocol approved by the Rwanda National Ethics Committee (RNEC 032/RNEC/2012) and Partners Institutional Review Board in Boston, MA (2009-P-001941/11; BWH). A verbal consent was obtained from each nurse-mentee. Names and other personal identifiers were excluded from datasets extracted for the analyses.

\section{Consent for publication}

Not Applicable.

\section{Competing interests}

The authors declare that they have no competing interests.

\section{Publisher's Note}

Springer Nature remains neutral with regard to jurisdictional claims in published maps and institutional affiliations.

\section{Author details}

${ }^{1}$ Partners In Health, Kigali, Rwanda. ${ }^{2}$ Partners In Health, Boston, USA. ${ }^{3}$ College of Medicine and Health Sciences, University of Rwanda, Kigali, Rwanda. ${ }^{4}$ Division of General Pediatrics, Boston Children's Hospital, Boston, USA. ${ }^{5}$ Institute for Healthcare Improvement, Addis Ababa, Ethiopia. ${ }^{6}$ Division of Global Health Equity, Brigham and Women's Hospital, Boston, USA. ${ }^{7}$ Ministry of Health, Government of Rwanda, Kigali, Rwanda. ${ }^{8}$ Northwestern University Feinberg School of Medicine, Chicago, USA. 'Department of Global Health and Social Medicine, Harvard Medical School, Boston, USA.

Received: 31 July 2017 Accepted: 16 February 2018

Published online: 23 February 2018

\section{References}

1. WHO: Reduction of Maternal Mortality: A Joint WHO/UNFPA/UNICEF/World Bank Statement. Geneva; 1999.

2. Senanayake H, Dias T, Jayawardena A. Maternal mortality and morbidity: epidemiology of intensive care admissions in pregnancy. Best Pract Res Clin Obstet Gynaecol. 2013;27:811-20

3. Wagstaff A, Claeson M, Hecht RM, Gottret P: Chapter 9 millennium development goals for health : what will it take to accelerate progress ? 2003.

4. WHO: Reported Information on Mortality Statistics. World Health Organization; 2014.

5. Alvarez JL, Gil R, Hernández V, Gil A. Factors associated with maternal mortality in sub-Saharan Africa: an ecological study. BMC Public Health. 2009;9:462.

6. Chopra M, Daviaud E, Pattinson R, Fonn S, Lawn JE. Saving the lives of South Africa's mothers, babies, and children: can the health system deliver? Lancet. 2009;374:835-46.

7. Patton GC, Coffey C, Sawyer SM, Viner RM, Haller DM, Bose K, Vos T, Ferguson J, Mathers CD. Global patterns of mortality in young people: a systematic analysis of population health data. Lancet. 2009; 374:881-92.

8. WHO: Maternal Mortality. WHO; 2014

9. Lincetto O, Mothebesoane-anoh S, Gomez P, Munjanja S: Antenatal Care. 2010

10. Carroli G, Rooney C, Villar J. How effective is antenatal care in preventing maternal mortality and serious morbidity? An overview of the evidence. Paediatr Perinat Epidemiol. 2001;15:1-42.

11. Ali AAA, Adam I. Lack of antenatal care, education, and high maternal mortality in Kassala hospital, eastern Sudan during 2005-2009. J Matern Fetal Neonatal Med. 2011;24:1077-8.

12. Dowswell T, Carroli G, Duley L, Gates S, Am G, Ggp P, Gülmezoglu AM, Khan-Neelofur D, Piaggio GG. Alternative versus standard packages of antenatal care for low-risk pregnancy. Cochrane Database Syst Rev. 2010;10:CD000934.

13. Gross K, Armstrong Schellenberg J, Kessy F, Pfeiffer C, Obrist B, Schellenberg JA. Antenatal care in practice: an exploratory study in antenatal care clinics in the Kilombero Valley, south-eastern Tanzania. BMC Pregnancy Childbirth. 2011;11:36.

14. Rani M, Bonu S, Harvey S. Differentials in the quality of antenatal care in India. Int J Qual Health Care. 2008;20:62-71.

15. Tetui M, et al. Quality of antenatal care services in eastern Uganda implications for interventions. PanAfrican Med J. 2012;13:1-15.

16. Maestad O TG: Improving the Quality of Health Care When Health Workers Are in Short Supply. Volume 12; 2008.

17. Blank A, Prytherch H, Kaltschmidt J, Krings A, Sukums F, Mensah N, Zakane A, Loukanova S, Gustafsson LL, Sauerborn R, Haefeli WE. "Quality of prenatal and maternal care: bridging the know-do gap" (QUALMAT study): an electronic clinical decision support system for rural sub-Saharan Africa. BMC Med Inform Decis Mak. 2013;13:44.

18. Wang W, Alva S, Wang S, Fort A. Levels and trends in the use of maternal health Services in Developing Countries. DHS comparative reports no. 26. Calverton, Maryland: ICF Macro; 2011.

19. Rowe AK, de Savigny D, Lanata CF, Victora CG. How can we achieve and maintain high-quality performance of health workers in low-resource settings? Lancet. 2005:366:1026-35.

20. Ameh C, Msuya S, Hofman J, Raven J, Mathai M, van den Broek N. Status of emergency obstetric care in six developing countries five years before the MDG targets for maternal and newborn health. PLoS One. 2012;7:e49938.

21. Logie DE, Rowson M, Ndagije F. Innovations in Rwanda ' $s$ health system : looking to the future. 2008;372(9634):256-61. 
22. Finlayson K, Downe S. Why do women not use antenatal services in lowand middle-income countries? A meta-synthesis of qualitative studies. PLoS Med. 2013;10:e1001373.

23. AHWO: Human Resources for Health: Country Profile Rwanda. WHO 2009:17-24.

24. Say L, Chou D, Gemmill A, Tunçalp Ö, Moller A-B, Daniels J, Gülmezoglu AM, Temmerman M, Alkema L. Global causes of maternal death: a WHO systematic analysis. Lancet Glob Heal. 2014;2:e323-33.

25. Zanconato G, Msolomba R, Guarenti L, Franchi M. Antenatal care in developing countries: the need for a tailored model. Semin Fetal Neonatal Med. 2006;11:15-20.

26. Ps R, Verma S, Rai L, Kumar P, Pai MV, Shetty J. "' Near miss "' obstetric events and maternal deaths in a tertiary care hospital : an audit. J Pregnancy. 2013;2013:10-5.

27. Satti H, Motsamai S, Chetane P, Marumo L, Barry DJ, Riley J, McLaughlin MM, Seung KJ, Mukherjee JS. Comprehensive approach to improving maternal health and achieving MDG 5: report from the mountains of Lesotho. PLoS One. 2012;7:e42700.

28. Sipsma HL, Curry LA, Kakoma J-B, Linnander EL, Bradley EH. Identifying characteristics associated with performing recommended practices in maternal and newborn care among health facilities in Rwanda: a cross-sectional study. Hum Resour Health. 2012;10:13

29. Villar J, Ba'Aqeel H, Piaggio G, Lumbiganon P, Miguel Belizán J, Farnot U, Al-Mazrou Y, Carroli G, Pinol A, Donner A, Langer A, Nigenda G, Mugford M Fox-Rushby J, Hutton G, Bergsjø P, Bakketeig L, Berendes H, Garcia J, WHO antenatal care trial research group. WHO antenatal care randomised trial for the evaluation of a new model of routine antenatal care. Lancet (London, England). 2001;357:1551-64.

30. Republic of Rwanda: National Reproductive Health Policy. Kigali; 2003.

31. Ouma PO, van Eijk AM, Hamel MJ, Sikuku ES, Odhiambo FO, Munguti KM, Ayisi JG, Crawford SB, Kager PA, Slutsker L. Antenatal and delivery care in rural western Kenya: the effect of training health care workers to provide "focused antenatal care". Reprod Health. 2010;7:1.

32. ACCESS: Focused antenatal care: providing integrated, individualized care during pregnancy. 2007

33. Vilar J BP: WHO Antenatal Care Randomized Trial. Manual for the Implementation of the New Model. World health Organization; 2003.

34. Fagbamigbe AF, Idemudia ES. Assessment of quality of antenatal care services in Nigeria: evidence from a population-based survey. Reprod Health 2015;12:88.

35. Ngabo F, Zoungrana J, Faye O, Rawlins B, Levine R, Sethi R, MacDowell J, Arscott-Mills S, Basinga P. Quality of Care for Prevention and Management of Common Maternal and Newborn Complications Findings from a National Health Facility Survey in Rwanda. Jhpiego; 2012.

36. Conrad P, Schmid G, Tientrebeogo J, Moses A, Kirenga S, Neuhann F, Müller O, Sarker M. Compliance with focused antenatal care services: do health workers in rural Burkina Faso, Uganda and Tanzania perform all ANC procedures? Trop Med Int Heal. 2012;17:300-7

37. Anya SE, Hydara A, Jaiteh LE. Antenatal care in the Gambia: missed opportunity for information, education and communication. BMC Pregnancy Childbirth. 2008;8:9.

38. Mbalinda SN, Nakimuli A, Kakaire O, Osinde MO, Kakande N, Kaye DK. Does knowledge of danger signs of pregnancy predict birth preparedness? A critique of the evidence from women admitted with pregnancy complications. Health Res Policy Syst. 2014;12:60

39. Pembe AB, Carlstedt A, Urassa DP, Lindmark G, Nyström L, Darj E. Quality of antenatal care in rural Tanzania: counselling on pregnancy danger signs. BMC Pregnancy Childbirth. 2010;10:35.

40. Majrooh MA, Hasnain S, Akram J, Siddiqui A, Memon ZA. Coverage and Quality of Antenatal Care Provided at Primary Health Care Facilities in the "Punjab" Province of "Pakistan." PLoS One 2014;9:e113390.

41. NUFFIC: The Rwandan education system described and compared with the Dutch system. 2015

42. Binagwaho A, Kyamanywa P, Farmer PE, Nuthulaganti T, Umubyeyi B, Nyemazi JP, Mugeni SD, Asiimwe A, Ndagijimana U, Lamphere McPherson H, Ngirabega J de D, Sliney A, Uwayezu A, Rusanganwa V, Wagner CM, Nutt CT, Eldon-Edington M, Cancedda C, Magaziner IC, Goosby E. The human resources for health program in Rwanda - a new partnership. N Engl J Med. 2013:369:2054-9.

43. Government of Rwanda. Rwanda Human Resources for Health Program 2011-2019: Funding Proposal. Kigali; 2011
44. Republic of Rwanda: Service Packages for Health Facilities at Different Levels of Service Delivery. Kigali; 2011.

45. Manzi A, Magge H, Redditt V, Karamaga A, Niyonzima S, Drobac P, Mukherjee JS, Ntaganira J, Nyirazinyoye L, Hirschhorn LR. Nurse mentorship to improve the quality of health care delivery in rural Rwanda. Nurs Outlook. 2012:61:137-44.

46. Magge H, Anatole M, Cyamatare FR, Mezzacappa C, Nkikabahizi F, Niyonzima S, Drobac PC, Ngabo F, Hirschhorn LR. Mentoring and quality improvement strengthen integrated management of childhood illness implementation in rural Rwanda. Arch Dis Child. 2014;100:565-70.

47. Manzi A, Magge H, Hedt-Gauthier BL, Michaelis AP, Cyamatare FR, Nyirazinyoye L, Hirschhorn LR, Ntaganira J. Clinical mentorship to improve pediatric quality of care at the health centers in rural Rwanda: a qualitative study of perceptions and acceptability of health care workers. BMC Health Serv Res. 2014;14:275.

48. National Institute of Statistics of Rwanda (NISR) [Rwanda], Ministry of Finance and Economic Planning (MINECOFIN): Rwanda Fourth Population and Housing Census. Kigali, Rwanda; 2012.

49. Leuchowius K: Report on the health care sector and business opportunities in Rwanda. Sweden; 2014

50. Goverment of Rwanda: Annual Report, July 2012-June 2013. Kigali; 2013.

51. National Collaborating Centre for Women's and Children's Health (UK): Antenatal Care: Routine Care for the Healthy Pregnant Woman. RCOG Press; 2008.

52. Vogel JP, Ndema HA, Souza JP, Gülmezoglu MA, Dowswell T, Carroli G, Baaqeel HS, Lumbiganon P, Piaggio G, Oladapo OT. Antenatal care packages with reduced visits and perinatal mortality: a secondary analysis of the WHO antenatal care trial. Reprod Health. 2013;10:19.

53. Bloom SS, Lippeveld T, Wypij D. Does antenatal care make a difference to safe delivery? A study in urban Uttar Pradesh, India. Health Policy Plan. 1999;14:38-48.

54. Makaka A, Breen S, Binagwaho A: Universal health coverage in Rwanda: a report of innovations to increase enrolment in community-based health insurance. Lancet 2012;380:S7.

55. African Development Bank: Performance Contracts and Social Service Delivery-Lessons from Rwanda. 2013.

56. Government of Rwanda: Districts Imihigo Evaluation Report. 2010.

57. Leslie HH, Gage A, Nsona H, Hirschhorn LR, Kruk ME. Training and supervision did not meaningfully improve quality of care for pregnant women or sick children in sub-Saharan Africa. Health Aff (Millwood). 2016;35:1716-24.

58. Tunçalp Ö, Pena-Rosas J, Lawrie T, Bucagu M, Oladapo O, Portela A, Metin Gülmezoglu A. WHO recommendations on antenatal care for a positive pregnancy experience-going beyond survival. BJOG An Int J Obstet Gynaecol. 2017:124:860-2.

59. WHO: WHO Recommendations on Antenatal Care for a Positive Pregnancy Experience. Geneva, Switzerland: World Health Organization; 2017.

\section{Submit your next manuscript to BioMed Central and we will help you at every step:}

- We accept pre-submission inquiries

- Our selector tool helps you to find the most relevant journal

- We provide round the clock customer support

- Convenient online submission

- Thorough peer review

- Inclusion in PubMed and all major indexing services

- Maximum visibility for your research

Submit your manuscript at www.biomedcentral.com/submit 